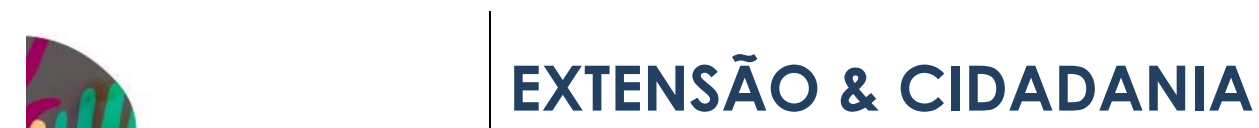

v. 8 , n. 13 , p. $185-200$, jan./jun. 2020 .

ISSN 2319-0566

DOI: $10.22481 /$ recuesb.v8i13.6084

\title{
CULTURA E SAÚDE: A EXPERIÊNCIA EM EXTENSÃO UNIVERSITÁRIA NO PROJETO RONDON EM ACARI (RN)
}

\section{CULTURE AND HEALTH: EXPERIENCE IN UNIVERSITY EXTENSION ON THE RONDON PROJECT IN ACARI (RN)}

\author{
Pedro Henrique Carnevalli Fernandes ${ }^{1}$ \\ Ruhama Ariella Sabião Batista ${ }^{2}$ \\ Micael Almeida de Oliveira ${ }^{3}$
}

\begin{abstract}
Resumo: A realidade social brasileira revela, cada vez mais, a necessidade das perspectivas acadêmicas e científicas se expandirem para as comunidades por meio da extensão universitária, gerando, inclusive, novos pressupostos e resultados. Diante disso, o Projeto Rondon tem se demonstrando uma ferramenta extensionista de bastante êxito. Nesse sentido, este artigo aborda a experiência em extensão universitária na Operação Forte dos Reis Magos 2016, do Projeto Rondon, no município de Acari (RN), pelas oficinas de "Cultura" e "Saúde", que contemplaram diferentes públicos da comunidade local: alunos, capacitação docente a sociedade. Os procedimentos metodológicos foram: levantamento bibliográfico acerca da extensão universitária, da cultura e da saúde, que alicerçaram a construção do material apostilado utilizado na aplicação das oficinas e, consequentemente, este artigo; realização das oficinas de extensão, descrevendo os resultados e promovendo as reflexões sobre elas, e, por fim, a sistematização da redação deste artigo. Os principais resultados foram: quanto à saúde, a conscientização acerca do não uso das drogas, sobretudo as ilícitas e, por último, quanto à cultura, amplo debate sobre a diversidade cultural potiguar e brasileira e valorização e manutenção dos aspectos culturais locais de Acari.
\end{abstract}

Palavras chave: Cultura. Extensão Universitária. Projeto Rondon. Saúde.

Abstract: The Brazilian social reality reveals the need for academic and scientific perspectives to expand to communities through university extension, generating even new assumptions and results. On this, the Rondon Project has been demonstrating a very successful extension tool. In this sense, this paper approaches the experience in university extension in the "Operation

\footnotetext{
${ }^{1}$ Doutor em Geografia, pela Universidade Estadual de Maringá (UEM); Docente do Colegiado de Geografia da Universidade Estadual do Norte do Paraná (UENP); Editor da Revista Geoingá. mail: pedrofernandes@uenp.edu.br

${ }^{2}$ Mestre em História, pela Universidade Estadual de Ponta Grossa (UEPG). Graduação em História pela UENP; Doutoranda do Programa de Pós-Graduação em Educação da UEPG. E-mail: ruhamasabiao@ hotmail.com

${ }^{3}$ Especialista em Residência Multiprofissional em Álcool e outras Drogas, pela Universidade de São Paulo (USP). Graduação em Enfermagem, pela UENP. E-mail: micaelalmeida@gmail.com
} 
Forte dos Reis Magos 2016" of the Rondon Project, in the Acari (RN), by the "Culture" and "Health" workshops, which included different publics of the local community: students, teacher training and the local society. The methodological procedures were: bibliographical survey about university extension and culture and health, which supported the construction of the apostilled material used in the application of the workshops and, consequently, this paper; conducting extension workshops, describing the results and promoting reflections on them; and, finally, the systematization of the writing of this paper. The main results were: regarding health, awareness about non-use of drugs, especially illicit drugs; as far as culture is concerned, broad debates on the Rio Grande do Norte and Brazilian cultural diversity, and the appreciation and maintenance of the local cultural aspects of Acari.

Keywords: Culture. University Extension. Rondon Project. Health.

\section{Introdução}

A realidade social brasileira revela, cada vez mais, a necessidade das perspectivas acadêmicas e científicas se expandirem para além dos limites da universidade, ou seja, para as comunidades locais, especialmente as menos assistidas, por meio da extensão universitária, gerando, inclusive, novos pressupostos e resultados. A extensão universitária se configura como uma forma de interação entre a universidade e a comunidade, sendo pensada a partir de uma relação dupla, de troca de conhecimentos entre os acadêmicos e as demais pessoas, como "influxos positivos em forma de retroalimentação, tais como suas reais necessidades, anseios e aspirações" (NUNES; SILVA, 2011, p. 120). Então, "é o processo educativo, cultural e científico que articula o ensino e a pesquisa de forma indissociável e viabiliza a relação transformadora entre universidade e sociedade" (NUNES; SILVA, 2011, p. 120).

O objetivo deste artigo é apresentar a experiência em extensão na realização de oficinas nas áreas de cultura e de saúde na "Operação Forte dos Reis Magos” do Projeto Rondon 2016, no município de Acari, no Seridó, do Rio Grande do Norte. Os objetivos específicos deste artigo são: contribuir com o debate teórico sobre os temas da cultura e saúde; demonstrar os procedimentos metodológicos em extensão e, por fim, refletir acerca da extensão universitária em consonância com a realidade do interior do Rio Grande do Norte.

Os procedimentos metodológicos para a realização deste artigo foram: levantamento bibliográfico acerca dos temas e transversais a eles, descrição e análise das práticas e da preparação do projeto de extensão, descrição, análise e registro fotográfico da realização das 
oficinas de extensão durante a operação e, finalmente, sistematização dos resultados na elaboração da redação final deste artigo.

O Rio Grande do Norte é uma Unidade da Federação do Brasil que pertence à Região Nordeste. As faces Norte e Leste do Estado são litorâneas, com extensão de 410 quilômetros, banhadas pelo Oceano Atlântico. A área do Estado é de 52.811 quilômetros quadrados e a população absoluta de 3.168.027 habitantes, gerando uma densidade demográfica de 60 habitantes por quilômetro quadrado (IBGE, 2010; RIO GRANDE DO NORTE, 2016). O Estado é dividido geograficamente em quatro Mesorregiões: Leste Potiguar, Agreste Potiguar, Central Potiguar e Oeste Potiguar (IBGE, 2010), acompanhando a subdivisão nordestina, com características semelhantes da Zona da Mata, do Agreste e do Sertão.

O município de Acari está localizado na Mesorregião Central Potiguar e, dentro dela, na Microrregião do Seridó Oriental (IBGE, 2010), possuindo, portanto, características típicas do Sertão nordestino. O município de Acari tem 11.035 habitantes, sendo que cerca de $80 \%$ residem em área urbana (IBGE, 2010), e compõe o Polo Seridó, reconhecido pelo turismo rural baseado na Caatinga (RIO GRANDE DO NORTE, 2015). A Figura 1 apresenta uma fotografia da área central da cidade de Acari, em 2016.

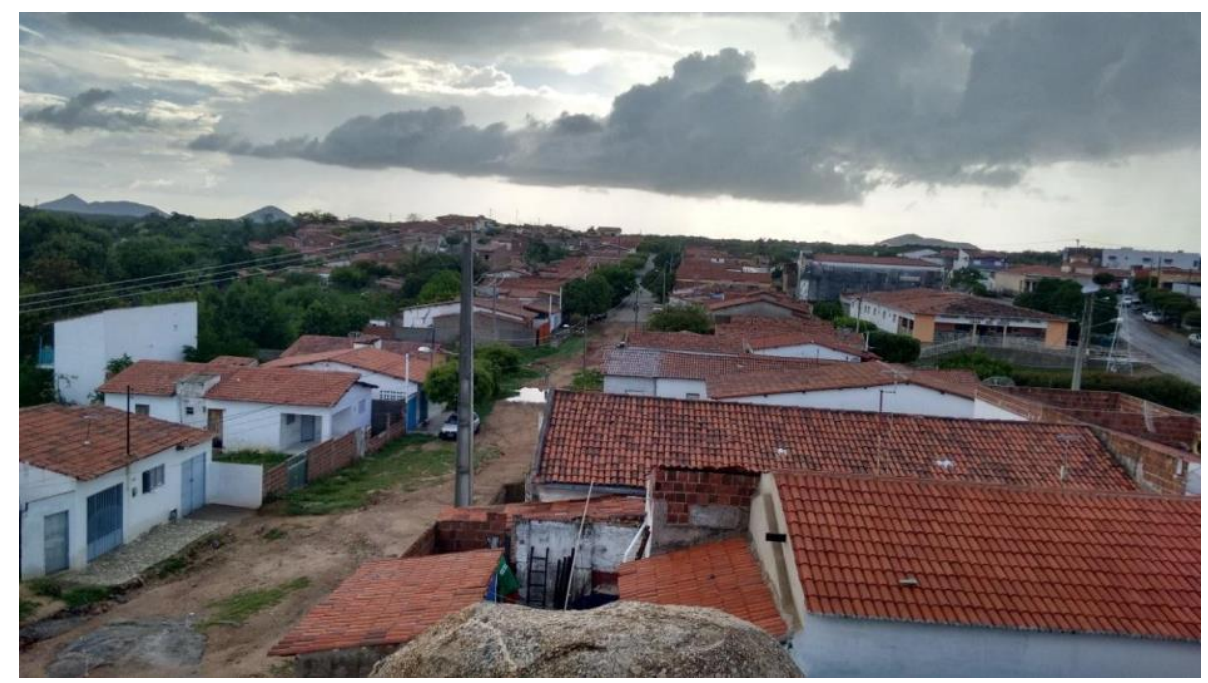

Figura 1: Acari (RN). Vista parcial da cidade, 2016.

Fonte: Pedro Henrique Carnevalli Fernandes, 2016.

A economia local se alicerça nos serviços $(50 \%)$ e na pecuária e agricultura (40\%), os indicadores sociais mais graves são: IDH baixo $(0,679)$, ausência de coleta de esgoto em $25 \%$ dos domicílios, rendimento mensal per capital de $\mathrm{R} \$ 328,00$ e $62 \%$ da população total em

\begin{tabular}{l|l}
\multirow{2}{*}{ REVISTA } & EXTENSÃO \& CIDADANIA \\
\cline { 2 - 3 } & v. 8, n. 13, p. 185-200, jan./jun. 2020. ISSN 2319-0566
\end{tabular}


situação de pobreza (ACARI, 2017). No município, a maior atração turística até meados de 2012 era o Açude Marechal Dutra, conhecido como "Gargalheiras", inaugurado em 1959, contudo, desde 2010, o açude encontra-se seco, resultado de anos de forte seca em Acari.

\section{O Projeto Rondon e a Operação Forte dos Reis Magos}

O Projeto Rondon surgiu durante o Regime Militar (1964-1985) com o lema "Integrar para não entregar", uma vez que as regiões brasileiras do Centro-Oeste, do Norte e do Nordeste eram consideradas relativamente pouco conhecidas e exploradas (RONDON, 2016). A primeira operação, denominada de “Operação Zero", aconteceu em julho de 1967 no Território Federal de Rondônia (atual Estado de Rondônia), durou quase um mês e contou com uma equipe de trinta universitários e dois professores. Em 1968, essa iniciativa foi institucionalizada com o nome "Projeto Rondon", em homenagem ao bandeirante paulista Marechal Cândido Mariano da Silva Rondon (RONDON, 2016). Em 1989, o Projeto Rondon foi extinto, após o hiato de 15 anos, o Projeto Rondon foi reativado em 2004, pelo presidente Luiz Inácio Lula da Silva com base em uma proposta de reformulação realizada pela União Nacional dos Estudantes (UNE). No ano seguinte, em 2005, aconteceu uma nova operação, denominada de "Operação Acre" e realizada no Estado do Acre (RONDON, 2016).

Os atuais objetivos do projeto são: proporcionar ao estudante universitário conhecimento de aspectos peculiares da realidade brasileira; contribuir com o fortalecimento das políticas públicas, atendendo às necessidades específicas das comunidades; desenvolver no estudante universitário sentimentos de responsabilidade social, espírito crítico e patriotismo; contribuir para o intercâmbio de conhecimentos entre as instituições de ensino superior, governos locais e lideranças comunitárias (RODON, 2016).

A Operação Forte dos Reis Magos foi realizada durante o mês de julho de 2016, em dez municípios do Estado do Rio Grande do Norte. Na operação, 21 Instituições de Ensino Superior (IES) participaram, sendo duas em Acari (RN). O nome da operação foi baseado em um dos mais relevantes pontos turísticos do Estado, o Forte dos Reis Magos (RONDON, 2016). Em Acari, a passagem do Projeto Rondon ajudou a plantar sementes de diferentes temas, descontruindo uma série de perspectivas coronelística do interior brasileiro, inclusive de manutenção do poder. Nesse sentido, as oficinas desenvolvidas na área de Cultura 
contemplaram a valorização da cultura local, a música, a dança, o teatro e o cinema e a construção de fantoche. Já na área de saúde as oficinas contemplam, predominantemente, o tema das drogas (ilícitas e lícitas), considerando a multiplicidades das características e das vivências dos públicos estimados.

\section{Cultura: valorização local e intercâmbio cultural}

Se o sertão está dentro da gente, não estranha que o sertão esteja em toda parte, que o sertão seja o mundo.

(Guimarães Rosa)

A cultura é uma teia de significados e sentidos, de acordo com Clifford Geertz (1989), aos quais os próprios sujeitos teceram e que somente através das expressões sociais e de uma ciência interpretativa é possível adentrar nessas teias. Além disso, cultura pode ser considerada "um complexo de conhecimentos e toda habilidade humana empregada socialmente" (SILVA; SILVA, 2009, p. 85). Nessa perspectiva, o Brasil é composto por várias teias, conhecimentos e habilidades humanas, com complexidade e magnitude dificilmente descritíveis.

Em um país com proporções continentais como o Brasil, falar em cultura é remeter-se à diversidade de cores, sons, artes, costumes, culinária e tudo o que remete ao âmbito cultural. Do Sul ao Nordeste, os brasileiros representam diferentes povos, tradições, práticas, que formam o que se conhece por Brasil, nacional ou internacionalmente. Dessa forma, sabe-se que não é exclusivamente o país do futebol, do carnaval e das praias, e que adentrá-lo é ao mesmo tempo uma tarefa árdua e prazerosa. Por isso, o Projeto Rondon, além de possibilitar a extensão na formação acadêmica, leva os participantes ao que pode ser chamado "intercâmbio cultural", no interior do próprio país.

No conhecer e caminhar pelas terras potiguares, no caso da Operação Forte dos Reis Magos, em Acari, é que se pode entender um pouco da imensidão do país, nos aspectos geográficos, históricos e culturais. Assim, foram elaboradas cinco oficinas na área cultural, sendo que elas ocorreram ao menos três vezes cada uma: (i) Valorização da cultura local; (ii) Cine Brasil: intercâmbio cultural; (iii) Música e Dança na escola; (iv) Teatro da melhor idade: manifestação cultural; e, (v) Construção de Teatro de Fantoche. Além disso, foi montada uma Tenda Cultural na Praça do Coreto, no centro da cidade, que ficou ativada e desenvolvendo 
atividades de artesanato, fotografia e cultura durante toda a operação.

De acordo com os trabalhos produzidos por pesquisadores da Universidade Federal do Rio Grande do Norte (UFRN), Campus de Caicó, a historiografia regional tem se preocupado em não somente desconstruir uma história oficial, mas reconstruí-la a partir dos estudos sobre a sociedade, assumindo diferentes abordagens (MACEDO; ARAÚJO; SANTOS, 2011). O regional não é entendido apenas como espaço geográfico, mas também como expressão cultural e de identidade, nas quais foi formada a região chamada "Seridó Potiguar" (CAVIGNAC, 2003; MACEDO, 2004, 2011). Para isso, é necessário o olhar para os diferentes grupos e sujeitos sociais, tais como os índios, negros, mulheres e outros grupos que não se inseriram em um primeiro momento na história oficial (MACEDO; ARAÚJO; SANTOS, 2011).

Logo, as pesquisas realizadas sobre Acari e o Seridó potiguar se voltaram para a história local, para o turismo e para a caracterização ambiental da região, principalmente para serem aplicadas à oficina voltada para os gestores, mas também aos alunos e professores que estavam presentes nas oficinas. A maioria das atividades de cultura foi concentrada na "Tenda Cultural", apresentada na Figura 2. Esse espaço funcionou como um ponto de encontro entre o Projeto Rondon e a comunidade local.

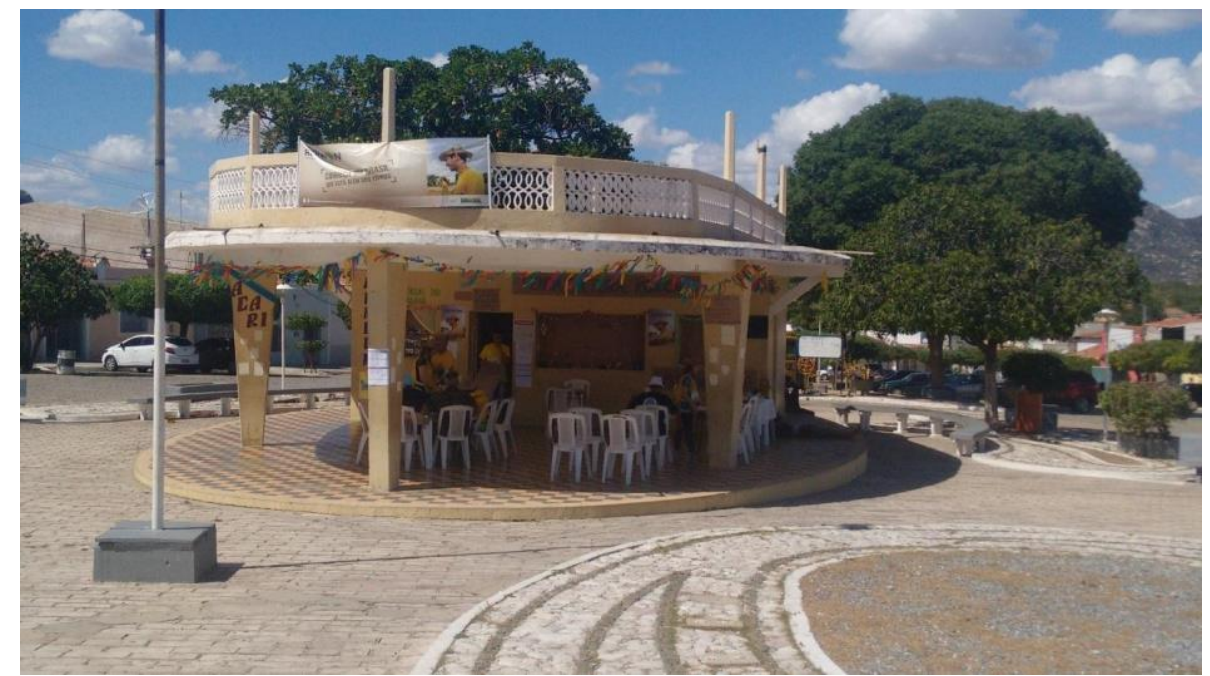

Figura 2: Acari (RN). Tenda Cultura, 2016.

Fonte: Pedro Henrique Carnevalli Fernandes, 2016.

Ao longo do período, aconteceram atividades de artesanato, produção de fantoches, fotografia, filmes, música, entre outros. Em algumas noites, todos os rondonistas ficavam na Tenda Cultural, momento no qual a relação com a comunidade se tornava mais estrita. As outras

\begin{tabular}{l|l}
\multirow{2}{*}{ REVISTA } & EXTENSÃO \& CIDADANIA \\
\cline { 2 - 3 } & v. 8, n. 13, p. 185-200, jan./jun. 2020. ISSN 2319-0566
\end{tabular}


oficinas de cultura foram realizadas em escolas, na Secretaria Municipal de Educação, no Lar dos Idosos e no Distrito de "Gargalheiras", chamada de Vila dos Pescadores.

A oficina "Valorização da cultura local" teve como objetivo principal valorizar a história da cidade na perspectiva de desconstruir os mitos de criação. Essa oficina foi direcionada aos gestores e à comunidade, sendo realizada em três momentos distintos. Em um momento inicial, a oficina teve o intuito de apresentar o Projeto Rondon, no coreto da praça central, falando do que seria realizado com a comunidade nos dias em que os rondonistas estariam em Acari; em um segundo momento, os rondonistas se dirigiram à Secretaria Municipal de Educação e a oficina foi aplicada aos gestores de cultura do município; e em um momento final, a oficina foi realizada em formato de festival, com teatro, poesia, e dança, envolvendo os rondonistas e toda a comunidade.

Para os gestores, a oficina foi planejada com o intuito de instruí-los a pensar a gestão de cultura no município, organizando todas as instituições, grupos, festas e características geográficas. Para isso, foram apresentados alguns projetos de cultura, tanto no Rio Grande do Norte como em outros estados, como: Casas de Cultura Popular (RN); Agentes de Leitura (PR); Fábricas de Cultura (SP); Um dia de arte (PR); e, Festival Permanente de Cultura (PR). Além disso, foi apresentado o documento do Ministério de Cultura "Como fazer um plano de cultura" (BRASIL, 2013), com o fim de orientar os gestores a criarem um plano de cultura para Acari, que fosse permanente e pensado em longo prazo. Esse plano existe em algumas outras cidades, como Criciúma (SC), São Paulo (SP), Campo Grande (MS), que também foram expostos, a título de exemplo.

Para a comunidade, a oficina aconteceu concomitante à tenda cultural, na qual se buscou ressaltar as poesias potiguares, acarienses e também paranaenses. Visto que o Projeto Rondon interliga diferentes culturas e regiões do Brasil, procurou-se apresentar também o Paraná, onde há também grande diversidade de culturas. Para isso, foi feito uma "janela" descrita como "Memórias do Paraná", com fotografias: dos campi da Universidade Estadual do Norte do Paraná; dos rondonistas em pontos turísticos do Paraná; e fotos diversas de lugares das cidades principais e também do interior do Paraná.

Ainda na tenda, no último dia, foi apresentado um teatro para a comunidade, em que alunos do primeiro e terceiro ano Ensino Médio do Colégio Dr. José Gonçalves de Medeiros atuaram conjuntamente com um rondonista a peça adaptada "Morte e Vida Severina". No 
mesmo dia foi recitado um poema escrito por uma das rondonistas, em que sintetiza as suas pesquisas, conversas com a comunidade local e andanças por Acari ao longo do projeto:

\section{Memórias das Gargalheiras de Acari}

Ruhama Ariella Sabião Batista

Vou lhes contar uma história, de certo lugar que um dia conheci, pequena em habitantes, mas grande de coração, esse lugar chama-se Acari.

Fica no Seridó Oriental do Rio Grande de Norte, região bonita e tão cheia de histórias, - mas que sorte!

Não sei tudo de lá, porque minha origem é do Norte do Paraná, entre pinheiros, cataratas e café,

tenho certeza companheiro, do nosso Estado você ia gostar até!

Mas vamos voltar a Acari,

Por montanhas e paisagens naturais,

a natureza e as bênçãos de lá são sem iguais.

Sabe-se também que no Rio Grande do Norte, o Acari é afamado, que saudade das gargalheiras cheias, que volte a nós esse bem tão amado.

Dizem que lá é a "cidade mais limpa do Brasil" e quer saber companheiro? Esse é mesmo o seu perfil.

Já dizia uma lei antiga "todos são obrigados a ter limpado as frentes de suas casas."

$\mathrm{E}$, a partir dessa lei, virou costume que nem um poeirão arrasa.

Segundo o prefeito José Braz de Albuquerque Galvão, "nesta cidade o 'sugismundo' não pode morar",

esse era um lema da época, tão engraçado de lembrar.

Vamos falar agora dos primeiros habitantes daqui, segundo as histórias oficiais, esses foram os primeiros a desbravar:

Manuel Esteves de Andrade e Tomaz de Araújo Pereira, mas nem que se queira, não podemos esquecer, que antes aqui viviam os Índios Cariris.

Luis Câmara Cascudo, importante historiador potiguar, nos diz que nas margens do Rio Acauã, eles vieram a morar.

Com muitas guerras, matanças e perseguições, da sua história pouco foi escrito e lembrado, mas não podemos nos esquecer do seu importante legado.

Em terras estranhas, os portugueses chegaram, mas aqui já havia gente, como então posso dizer que sou somente seu descendente?

Por que "Acari", me pus a perguntar,

descobri que acaris eram peixes, que no Rio Acauã eram facinhos de pescar.

Conta a lenda que a história de um tal de Felipe não terminou bem, de origem pobre e sem dinheiro pra sustentar seu filho e seu amor saiu pela vida desejando favor.

Voltou à cidade rico e com esperança de a moça e o filho encontrar, mas que decepção, a moça tinha mandado o filho ao rio para se afogar,

Felipe triste e decepcionado, no Rio Acauã viu sua história acabar.

Por essa história triste,

Nós sabemos que hoje lá existe, o Poço do Felipe. 
Mas então a história continua, Acari cresce e tão bonita se insinua.

Foi chegando gado e construída uma igreja,

N.S. da Guia, que bonita - veja!

Por entre as fazendas o pessoal foi crescendo, e a "cidade mais limpa do Brasil" ia se fazendo.

Aqui tem sobrenomes bonitos, que grande parte da população tem,

mas não nos esqueçamos da importância dos outros nomes também.

Todos os sujeitos são importantes na construção de uma cidade,

crianças, adolescentes, adultos ou idosos, não importa a idade!

Acari tem muitas atrações, isso se vê de prima,

tem museu, tem pega do boi-do-mato e também a festa junina.

Cheia das fazendas, cada uma com sua beleza

Pitombeira, Ingá, Belém, Caiçarinha, Pinturas e muitas outras com certeza.

Na serra do Bico de Arara, os andarinhões fazem a farra,

Eles estão lá todos os dias há mais de um século demonstrando beleza rara.

No Poço do Artur, ali escondidinho, um sítio arqueológico tem,

Ouvi dizer que os índios ali deixaram itacoatiaras, que significa pedra riscada em tupi,

Que sorte dos acarienses constatar que nossos antepassados estiveram por aqui.

Eu teria muita coisa pra falar, mas já estou quase a encerrar.

Ouvi que nessa cidade já teve até gente que estrelou o filme do Zorro de graça, só para sua cidade alegrar.

Me parece que o futebol aqui é muito popular das crianças aos adultos, todos vibram ao jogar.

"Seu" Zé Nunes que o diga, quanto fez pra incentivar.

Por aqui vou me despedindo, levando no peito essa cidade.

E como em Acari tudo termina e recomeça num 'pronto':

PRONTO, agora queremos saber, o que Acari significa para você?

A oficina "Música e dança na escola" foi destinada a professores e alunos. Para os professores o objetivo principal foi ressaltar a diversidade de possibilidades do uso da música e da dança na sala de aula, em todas as disciplinas, e também mostrar a diversidade cultural presente no Brasil por meio das danças. Para os alunos, foi trabalhada a questão de gênero na música e na dança, bem como a importância desses itens para o desenvolvimento físico e social. Foi produzido um vídeo no qual foram agregadas diferentes danças culturais brasileiras: Baião (Nordeste); Calango (Minas Gerais); Chula (Rio Grande do Sul); Pau-de- fitas (Paraná); Carimbó (Pará); Dança do Boi (Amazonas); Samba de Gafieira (Rio de Janeiro); Espontão (Rio Grande do Norte); Danças urbanas (São Paulo e Santa Catarina); Catira (Goiás); Xaxado e Frevo (Pernambuco); Forró (Nordeste); Movimento de Águas Iemanjá (Religiões de matriz africana); Canto Sagrado da Mãe Terra (Tribo Fulni ô, Aldeia Multiétnica). Os rondonistas buscaram mostrar que a música e a dança estão presentes na cultura, na religião, nas festas, e que são para todas as pessoas. 
A oficina "Cine Brasil: intercâmbio cultural" intentou atingir a toda a comunidade, portanto, esteve nas escolas, na tenda cultural e no lar dos idosos, foram apresentados somente filmes nacionais com o fim de valorizar a produção nacional e debater o contexto de cada filme, buscando questões de crítica social e cultural por meio da exibição dos filmes.

\section{Saúde: Drogas - Prevenção da Infância à Juventude}

Ao longo de sua história, o homem tem recorrido continuamente ao uso de substâncias psicoativas, como álcool, fumo e outras drogas para rituais religiosos, para se livrar do sofrimento ou para atingir o prazer. Os cenários, as razões e as novas formas de aquisição das substâncias psicoativas mudaram muito ao longo dos tempos, tendo características próprias de acordo com cada período e cada sociedade em que está agregado, levando a condições distintas de vulnerabilidades (BRASIL, 2006). O consumo de substâncias psicoativas popularmente referidas como "drogas" remontam a lugares longínquos e há tempos imemoriais (LABATE et al., 2008). A Organização Mundial de Saúde (OMS, 2002) define como droga qualquer substância não produzida pelo organismo que tem a propriedade de atuar sobre um ou mais de seus sistemas, gerando alterações em seu funcionamento, ou seja, altera ou causa uma série de mudanças na forma de sentir, pensar, agir e expressar. $\mathrm{O}$ aumento do consumo abusivo de drogas nas últimas décadas configurou, na sociedade, um sério problema que exige “integralidade nas ações das políticas públicas para minimizar as consequências de possíveis agravos à saúde" (BRASIL, 2006, p. 13).

Entre os mais afetados por esse crescimento exponencial do consumo e abuso de substâncias psicoativas estão os jovens. O que pode ser explicado pela ambivalência experimentada na juventude, que alterna dúvida e construção de certezas, manifesta momentos de desequilíbrio e descontentamento, servindo como um alvo fácil para simbolizar os dilemas da contemporaneidade (FEFFERMAN, 2004).

O VI Levantamento Nacional sobre o Consumo de Drogas Psicotrópicas entre Estudantes do Ensino Fundamental e Médio, lançado em 2010, realizado em 27 capitais brasileiras, pela Secretária Nacional de Políticas sobre Drogas (SENAD), em conjunto com o Centro Brasileiro de Informações sobre Drogas Psicotrópicas, da Universidade Federal de São Paulo (CEBRID/UNIFESP), mostra que os jovens estão experimentando drogas cada vez mais 
precocemente, sejam as legais ou as ilegais (CEBRID, 2010).

Ao que toca o âmbito de programas, projetos e iniciativas de prevenção ao uso de drogas no Brasil, presencia-se a uma catástrofe por ser utilizado um modelo pautado em princípios morais, no amedrontamento do público e sendo realizado por grupos distintos, cada qual se pautando naquilo que lhe compete, desfragmentado o indivíduo, deixando de lado a ideia de um sujeito biológico, social, cultural e econômico, além de ignorar as subjetividades do ser jovem. Diante desse contexto, a redação desta seção do artigo se alicerça em literatura e métodos comprovadamente eficazes para a prevenção do uso e abuso de drogas, assim como estratégias de redução de agravos para aqueles que já fizeram ou fazem uso de algum tipo de substância psicoativa. De acordo com as Normas Internacionais sobre a Prevenção do Uso de Drogas do Escritório das Nações Unidas sobre Drogas e Crime (UNODC), a prevenção é um dos principais componentes de um sistema de saúde focado para abordar a questão das drogas.

\begin{abstract}
O principal objetivo em prevenir o uso de drogas é ajudar pessoas, principalmente, mas não exclusivamente, os jovens, a fim de evitar ou retardar o início do uso de drogas, ou, se já iniciaram, evitar que desenvolvam transtornos (por exemplo, a dependência). O objetivo geral da prevenção do uso de drogas, no entanto, abrange muito mais que isso, ele busca o desenvolvimento seguro e saudável de crianças e jovens, de forma que percebam seus talentos e potenciais, tornando-se membros que contribuam para o bem de suas comunidades e da sociedade. Um sistema eficaz de prevenção do uso de drogas contribui significativamente para que crianças, jovens e adultos participem de forma positiva nas atividades familiares, escolares, comunitárias e no ambiente de trabalho. (UNODC, s.d., p. 1)
\end{abstract}

As oficinas sobre drogas foram desenvolvidas a partir da demanda encontrada por meio da viagem precursora e foi incluída no eixo de saúde para três públicos distintos: alunos do Ensino Fundamental e Médio; população em geral e funcionários do Conselho Tutelar. Cada uma delas possuía tanto conteúdo em comum como conteúdos específicos. Para este artigo, focalizam-se os resultados com as oficinas desenvolvidas para o público jovem.

As substâncias psicoativas escolhidas para serem abordadas na oficina voltada aos jovens foram as que aparecem como as mais consumidas no VI Levantamento Nacional sobre o Consumo de Drogas Psicotrópicas entre Estudantes do Ensino Fundamental e Médio, sendo elas: a maconha e cocaína, entre as ilícitas, o álcool e o tabaco, entre as lícitas. Para conceituar e descrever essas drogas foi utilizado o CEBRID (2010).

Para fins didáticos e pedagógicos, foi confeccionada uma apresentação de slides, 
sintetizando os achados na revisão bibliográfica por meio de figuras, tópicos e músicas. A estruturação dos slides foi pensada com o intuito de trazer conceitos baseados em evidências científicas por meio de uma linguagem acessível à idade e ao local de inserção social desses jovens, valorizando o conhecimento pré-existente e desmistificando aquilo que poderia surgir no decorrer da atividade.

As oficinas aconteceram em duas escolas estaduais do município de Acari, ministradas para alunos do Ensino Fundamental e Médio por dois rondonistas, acontecendo dentro das próprias salas de aula, foi utilizado aparelho de projeção multimídia para a exibição da apresentação em formato de slides e também a execução de músicas, escolhidas durante a formulação das oficinas, como forma de manifestação artística e cultural acerca da temática.

Sendo as drogas um assunto polêmico e que instiga, em especial aos jovens, não houve dificuldade em cativar ou necessidade de requerer a atenção do público, que variavam de vinte a quarenta alunos por sala. Logo, nos primeiros slides, onde era questionado e definido o que são drogas, as turmas, sem exceção, iniciavam a participação na atividade, interagindo por meio de respostas quando indagados sobre o conhecimento prévio e perguntas acerca da temática. Assim, de forma dialogada, a atividade perpassava por caminhos onde era estimulada uma discussão ampla sobre as drogas. No decorrer da atividade, foi criado um ambiente de troca de conhecimentos, de dúvidas que perpassavam diversas ordens sobre o tema, que muitas das vezes era a dúvida de todos os presentes.

A UNODC (s.d.) apresenta evidências de características associadas aos resultados negativos e aos positivos de prevenção do uso de drogas em diferentes fases da vida, desde a primeira infância até a vida adulta. Em relação à adolescência, público-alvo da oficina em questão, as características associadas aos resultados negativos são justamente as que os programas espalhados pelo Brasil apresentam, sendo alguns deles: entregar somente as informações, despertando o medo, utilizam guardas policiais para aplicar o programa, concentram-se apenas na construção da autoestima e educação emocional e incluem a participação de ex-usuários de drogas com depoimentos.

O uso de métodos interativos, a percepção do impacto dos riscos associados com o abuso de substâncias, enfatizando as consequências imediatas, a desconstrução dos equívocos sobre a natureza normativa e as expectativas ligadas ao abuso de substâncias, entre outras, são consideradas características associadas aos resultados positivos de prevenção, portanto, a 
oficina foi construída sob esse embasamento.

Após abordar um conteúdo introdutório sobre as drogas, foi realizada uma atividade de fortalecimento das habilidades pessoais e sociais. Essa atividade foi muito satisfatória para o desenvolvimento da oficina, pois foi um momento em que se pode perceber que a cidade contava com um leque de atividades e iniciativas voltadas ao público jovem, entre elas: Polícia Mirim, Escoteiros, Banda Municipal, etc. Também pode ser percebido o engajamento individual dos presentes em atividades extracurriculares.

A apresentação que se sucedeu foi a das drogas lícitas, sendo que as escolhidas para abordagem foram o álcool e o tabaco, as mais usadas, tanto pela população em geral, como pelos jovens. Após uma explanação participava sobre o sentido da licitude de uma substância, seguiu-se para uma breve história e conceituação sobre o tabaco, as formas de uso, os componentes do cigarro e seus efeitos agudos (curto prazo) e os efeitos crônicos (longo prazo). Foi recordado que, apesar de ser uma droga lícita, o tabaco tem sua venda proibida para menores de 18 anos.

Em seguida, foi conversado sobre o álcool, assunto delicado, visto que é a droga mais usada pelos jovens. O álcool é uma das poucas drogas psicotrópicas que tem seu consumo admitido e até mesmo incentivado pela sociedade, que é percebido pela veiculação de propagandas televisivas, que sempre relacionam o uso dessa droga com sucesso profissional, reunião de amigos e relações afetivas. Nesse caso, também foi recordado que apesar de ser uma droga lícita, o álcool tem venda proibida para menores de 18 anos.

Devido à complexidade em abordar o álcool, foi dedicado um tempo maior a discussão, que além de serem falado sobre sua história, formas de uso e de disponibilidade no mercado e efeitos estimulantes e depressores também foram tratados acerca do efeito dessa droga nas mulheres, efeitos em longo prazo e efeitos especificamente nos jovens, levando em consideração a fase de desenvolvimento em que se encontram.

Posteriormente, foi debatido o conteúdo sobre as drogas ilícitas, foi apresentado um breve histórico sobre a maconha, sua forma de apresentação na natureza, suas formas de consumo, a diferenciação entre criminalização, descriminalização, legalização e a liberação do uso dessa droga, assim como o cenário nacional e mundial. Em seguida, foi conversado sobre os efeitos físicos agudos e do que se tratavam os efeitos psíquicos agudos, assim como os efeitos físicos e psíquicos crônicos. 
Não menos importante, mas encerrando a apresentação, foi falado sobre a cocaína, apresentadas as formas em que é encontrada, na natureza ou mesmo para comercialização. Foram abordados sobre suas formas de uso, seus efeitos psíquicos agudos e crônicos. A apresentação foi preparada com muito afinco durante meses, e era melhorada e mudada a cada nova leitura, a cada novo olhar. Buscou-se pensar em uma abordagem eficaz que fosse baseada em um método de prevenção do uso de drogas. Relativizando sempre as evidências científicas com o contexto social, econômico e cultural do munícipio, em especial do público jovem.

\section{Considerações Finais}

No meio do sertão do Seridó potiguar, na chegada do projeto, visualizava-se a pequena cidade de Acari com uma melancólica por decorrência da seca e, principalmente, pelo distanciamento das políticas públicas em consonância com a realidade local. Por isso, percebese que projetos de extensão, como o Projeto Rondon, são fundamentais ferramentas de integração social e, sobretudo, de compartilhamento de conhecimento, informação e de valorização das localidades interioranas do Brasil.

Do outro lado, a participação dos universitários na comunidade, por meio da extensão, possibilita conhecer outras faces da realidade social do país que muitas vezes passam despercebidas nas salas de aulas. Além disso, contribui com o desenvolvimento de um estudante universitário mais responsável e mais crítico frente à multiplicidade da realidade brasileira, principalmente a de desigualdade.

Neste artigo, a opção por trazer dois eixos temáticos tão distintos, cultura e saúde visou demonstrar que ainda que com metodologias, temas e conteúdos e abordagens próprias, ambas apresentaram resultados parecidos quando de sua materialização na comunidade local, ou seja, mais relevante do que debater especificamente os temas de saúde e de cultura. Este artigo transitou pelos resultados, revelando que, independentemente do tema, é a transformação de todos os envolvidos que tem mais significância.

As oficinas de cultura buscaram promover um intercâmbio cultural entre rondonistas e população local, intentando sempre a troca de experiências e práticas, com um aprendizado mútuo. Ainda que todas as oficinas tenham sido previamente elaboradas, por meio de pesquisas bibliográficas, foi somente no contato e relacionamento com a população local que se pode 
adaptar melhor ao contexto dos acarienses. Acredita-se, assim, que a Operação Forte dos Reis Magos, na cidade de Acari, foi uma das "teias" que os rondonistas puderam entender e ajudar a "construir", afetando não só a formação acadêmica, mas influindo diretamente na concepção cultural e histórica local e do Brasil.

A oficina de saúde voltada para a prevenção de drogas, lícitas e ilícitas, buscou a prevenção ao uso de alguma droga, sendo que se espera que os participantes sirvam de multiplicadores do conteúdo que foi discutido, de forma respeitosa e somando os conhecimentos prévios apresentados, revelando os mitos e sanando as dúvidas de modo cuidadoso e confiável. É possível recolher como efeito dessa experiência a verdadeira essência da extensão universitária, o da interação universidade e comunidade, em que há sempre mais para trazer de volta do que aquilo que se leva.

\section{Referências}

ACARI, Prefeitura Municipal de. História e contexto atual. 2017. Disponível em: http://www.acari.rn.gov.br/178/DadosMunicipais/. Acesso em: 12 jul. 2017.

BRASIL. Ministério da Cultura. Como fazer um plano de cultura. São Paulo: Instituto Via Pública; Brasília-DF: MinC, 2013.

BRASIL. Ministério da Saúde. Secretaria de Atenção à Saúde. Departamento de Ações Programáticas Estratégicas. Guia estratégico para o cuidado de pessoas com necessidades relacionadas ao consumo de álcool e outras drogas. Brasília-DF: Ministério da Saúde, 2015.

CAVIGNAC, J.A. A etnicidade encoberta: 'índios' e 'negros' no Rio Grande do Norte. Mneme Revista de humanidades, Caicó, v. 4, n. 8, p. 1-79, abr./set., 2003.

CEDRIC. VI Levantamento Nacional sobre o Consumo de Drogas Psicotrópicas entre Estudantes do Ensino Fundamental e Médio das Redes Pública e Privada de Ensino nas 27 Capitais Brasileiras - 2010. São Paulo: CEBRID; UNIFESP, 2010.

FEFFERMANN, M. Vidas Arriscadas. 2004. Tese (Doutorado) - Faculdade de Psicologia, Universidade de São Paulo, São Paulo, 2004.

GEERTZ, C. A interpretação das culturas. Rio de Janeiro: Guanabara Koogan, 1989.

IBGE. Instituto Brasileiro de Geografia e Estatística. Censo demográfico de 2010. Disponível em: www.censo2010.ibge.gov.br. Acesso em: 4 jul. 2017.

LABATE, B. C. et al. Drogas e cultura: novas perspectivas. Salvador: EDUFBA,

\begin{tabular}{|c|c|}
\hline & EXTENSÃO \& CIDADANIA \\
\hline REVISTA & v. 8, n. 13, p. $185-200$, jan./jun. 2020. ISSN 2319-0566 \\
\hline
\end{tabular}


2008.

MACEDO, H. Populações indígenas no sertão do Rio Grande do Norte: história e mestiçagens. Natal: EDUFRN, 2011.

MACEDO, H.; MEDEIROS, F. Acari: berço da cultura e religiosidade na saga de um povo hospitaleiro. Natal: SEBRAE/RN, 2004.

MACEDO, H; ARAÚJO, D.; SANTOS, R. Seridó Potiguar: tempos, espaços, movimentos. João Pessoa: Ideia, 2011.

NUNES, A. L. de P. F.; SILVA, M. B. da C. A extensão universitária no ensino superior e na sociedade. Mal-Estar e Sociedade, Barbacena, ano IV, n. 7, p. 119-133, jul./dez. 2011.

RIO GRANDE DO NORTE, Governo do. Rio Grande do Norte: história, indicadores e fotos. Disponível em: www.rn.gov.br. Acesso em: 8 jul. 2017.

RONDON. História do Projeto Rondon. 2016. Disponível em:

http://www.projetorondon.defesa.gov.br/portal/index/pagina/id/9718/area/C/module/defaul. Acesso em: 8 jul. 2017.

SENAD. Secretaria Nacional de Políticas sobre Drogas. Brasília-DF: SENAD, 2010.

SILVA, K.V; SILVA, M. H. Dicionário de conceitos históricos. 2. ed. São Paulo: Contexto, 2009.

Recebido em: 3 de julho de 2018.

Aceito em: 9 de setembro de 2019. 